\title{
VENGANZA Y ENCIERRO COMO FUNCIONES RESTAURADORAS DEL ORDEN SOCIAL: UN ENFOQUE SIMBÓLICO-RITUAL DEL CRIMEN EN LA CULTURA WAYUU
}

\author{
Francisco Molina Ríos ${ }^{1}$ \\ Universidad de Zulia, Venezuela
}

http://dx.doi.org/10.5209/rev_NOMA.2013.42357

\begin{abstract}
Resumen.- Desde la perspectiva de la sociosemiótica, se muestra los ritos y mitos del crimen en la sociedad Wayuu que, por ser un pueblo originario, no cuenta con prisiones para los trasgresores de su ley, aún cuando tienen un código establecido de justicia oral. Existen signos que inducen a la venganza, practicado por los familiares de la víctima, como la utilización de elementos de color rojo, pero hay también otra acción ritual, conocida como el "encierro" para purificación del alma y la redención social, donde se restituye el imprescindible orden social entre los Wayuu, basada en su mitología originaria.
\end{abstract}

Palabras clave.- ritos wayuu, venganza, purificación, orden social

\section{Revenge and closure as functions restoring social order: A symbolic approach ritual of crime in the Wayuu culture}

\begin{abstract}
From the perspective of semiotics, we show the rituals and myths of crime in society Wayuu that, as an indigenous, has no prisons for offenders of the law, even when they have an established code of oral justice. There are signs that lead to revenge practiced by the family of the victim, as the use of red elements, but there is another ritual action, known as the "closure" for the purification of the soul and social redemption, which restores the essential social balance between the Wayuu, based on native mythology.
\end{abstract}

Keywords.- wayuu rites, revenge, purification, social order, wayuu

La cosmovisión wayuu es entendida como la convivencia con la naturaleza, de la cual se derivan los saberes y conocimientos que definen una forma de vida diferente a otras culturas y naciones [Jorge Pocaterra, 2009]

\footnotetext{
${ }^{1}$ Maestrante en Sociosemiótica de la Comunicación y la Cultura. Comunicador Social, mención Periodismo Audiovisual. Universidad del Zulia. Maracaibo, Venezuela.
} 


\section{INTRODUCCIÓN}

Desde tiempos originarios, todas las sociedades han implementado instrumentos que regulan la actuación y conducta de sus miembros para poder vivir armónicamente en compañía. Es así como surgieron patrones a seguir como los códigos morales, la estructura familiar, los lineamientos sociopolíticos y los sistemas jurídicos-normativos.

Al ahondar la investigación en la etnia Wayuu ${ }^{2}$, se descubre que su sociedad no escapa mucho de los patrones de orden social, aunque se diferencia marcadamente de la forma de hacer justicia en el mundo occidental, a pesar de su notable transculturización, con mayor marcación en las últimas décadas por los cinturones urbanizados de Venezuela y Colombia. Para los Wayuu, al igual que para muchas sociedades, es importante mantener el orden social dentro de su cultura.

El crimen, sin duda, es un elemento desequilibrante para cualquier organización social. En la vida occidental, los homicidios están penados por la justicia formal, enmarcado históricamente "por el Derecho Romano, la codificación napoleónica y las ideas heredadas de los filósofos racionalistas del siglo XVIII con su lógica cartesiana" (Segovia, 2007: www). Sin embargo los Wayuu no cuentan, como pueblo originario, con prisiones o cárceles para los trasgresores de su ley. Aún cuando tienen un código establecido de justicia oral, mas no escrita. Es a través de los rituales de la venganza, sólo en casos extremos de que no se logre o se rompa una indemnización previa, o del "encierro" con que se restablece el equilibrio social.

"Nosotros nunca hemos hecho cárceles, porque cada hombre sabe hasta dónde llega su derecho y cuándo lesiona el derecho de los demás. Eso lo persiguen los socialistas y los comunistas. Nosotros lo hemos practicado durante toda la historia, no es teoría, es hecho real. Nosotros no queremos que nadie crea en lo que nosotros creemos porque eso está hecho para que creamos nosotros solamente" (Montiel en Pereira, 2004: 47).

Desde un punto de vista más filosófico, el hombre siempre requiere la adquisición de nuevos conocimientos, a través del aprendizaje, lo que no le fue suministrado por nacimiento. Es allí la importancia que tiene el ser humano de vivir en sociedad y convivir con la cultura que le es trasmitida generacionalmente. "Creencias y mitos sobre el más allá, el destino del hombre, etc., acompañados de dogmas, tabúes y ritos son también parte de la cultura" (Briceño Guerrero, 1962:10).

Analizar esta serie de acciones rituales alrededor del crimen en la cultura Wayuu, de gran peso para el estudio sociosemiótico por su inmensa carga simbólica, es el objetivo fundamental de esta investigación, cuyo estudio documental se basa en la

\footnotetext{
${ }^{2}$ Descendentes de los Arawak, los Wayuu son el grupo más numeroso de indígenas que habitan Venezuela. Poblaron la Península de la Guajira, en el Zulia, y se extienden hasta la zona montañosa de los estados Trujillo y Mérida. Con la división geográfica de la Guajira, los Wayuu viven entre Venezuela y Colombia, portando ambas nacionalidades, pues ellos son anteriores al condicionamiento limítrofe.
} 
etnografía y la hermenéutica de textos y artículos referenciales sobre la cosmogonía y antropología Wayuu; así como de las entrevistas personalizadas.

\section{SOBRE LOS RITOS DE PURIFICACIÓN}

Sin duda el encierro de purificación del alma es visto como una acción ritual que busca la limpieza espiritual del hombre, contaminada por entes malignos-religiosos y, por ende, busca como fin ulterior restituir el orden social. Mary Douglas (1973: 13), desde la perspectiva antropológica de la escuela británica, indica que este tipo de rituales se remontan a viejos relatos religiosos, donde quien quiebre la angosta línea de lo prohibido al fomentar cualquier acción impura es castigado con "horribles desastres".

"Podría parecer que en una cultura ricamente organizada por ideas de contagio y purificación, el individuo está en las garras férreas de unas categorías de pensamiento que están poderosamente protegidas por reglas de prohibición y por castigos" (Douglas, 1973: 18).

De forma similar, Van Gennep (1969: 21) cataloga este tipo de rituales como indirectos o de contagios, pues necesita de una o varias potencias personificadas para su purificación "por ejemplo, un demonio o una clase de espíritus, o una divinidad, los cuales intervienen en beneficio de aquel que ha realizado el rito: voto, oración, cultos en el sentido habitual de la palabra. Etc".

$Y$ es que este encierro, a diferencia del denominado "blanqueo" y al también encierro de los sueños, se trata de la purificación de una suciedad que se lleva en el alma (dentro del cuerpo, por lo tanto no se ve; pero lo domina), y la cual crea esencialmente un desorden social entre los wayuu. Es entonces la función simbólica y referencia social de este rito lo que interesa, pues a través de esta acción es cuando se le consigue la solución a un grave problema, el cual es atendido bajo la cosmología mitológica Wayuu impregnada en su estructura social.

Precisamente es a través de los ritos, donde los mitos Wayuu se reactualizan y se vuelven contemporáneos con su práctica en el hombre, recitados en ceremonias que permite abolir la barrera temporal para dejar a un lado el presente e ir al pasado, a tiempos sagrados, por lo que estos ritos se convierten en experiencias únicas o como lo diría Roland Barthes (1990: 238), sólo en el mismo plano de la cultura y con el aplacamiento del entendimiento, la sociología "reconoce a los hombres el poder ilimitado de hacer que las cosas signifiquen".

\section{MITOLOGÍAS Y RITOS EN EL ORDEN SOCIAL WAYUU}

Para los Wayuu la tradición oral, transmitida de generación en generación, ha mantenido viva y vigente sus muy nutridos mitos y ritos desde épocas ancestrales. Son estos dos elementos, de gran importancia para su comunidad, las que 
refuerzan la cohesión social entre sus clanes y miembros, en medio de una sociedad indígena cargada de dramas y confrontaciones entre sí.

"En la vida cotidiana de esta comunidad, todos los elementos están íntimamente relacionados, siendo el mito el que orienta y le da sentido a la organización social, y esta a su vez recrea y alimenta la construcción de nuevos ritos" (Pinzón Sánchez, 1990:61-62).

Fue Claude Lévi-Strauss, padre del Estructuralismo antropológico, quien dio sentido al mito tras una larga investigación etnológica y cuyas características fundamentales, tomadas de estudios previos del historiador Mircea Eliade, las cuales fueron aceptadas por las diversas corrientes teóricas, quedando así establecidas: a) la consideración del mito como relato de la emergencia de los tiempos primordiales, b) el carácter sagrado del espacio mítico y c) el reconocimiento de su carácter social o colectivo.

En este sentido, es primordial diferenciar los mitos cosmogónicos y antropogónicos, donde se diferencia el origen de fundamento y de principio, siendo el primero el que explica la visión sobre la creación del mundo y, de esta manera, incluye el sentido antropogónico en sí a la vez, pues éste refiere a la creación del hombre; y ambos mitos de origen dan cuenta de los fenómenos del cosmos, de los seres y objetos que viven y existen en él, de los fenómenos sociales, políticos y económicos que acontecen entre los hombres.

José Enrique Finol (2007) manifiesta que el equilibrio entre el hombre y su grupo social se debe a los mitos creadores, los cuales nutren a sus miembros de las herramientas necesarias para la comprensión del mundo. En el caso de los Wayuu (o del pensamiento indígena generalizado) se trata de un equilibrio entre vivir o morir. Pero no solamente, señala el autor, se trata de contar el mito a la comunidad sino ponerlo en práctica al ser incorporado en la vida cotidiana.

"El mito es expresión de un sistema de valores culturales -axiológicos, ideológicos, políticos- que constituyen parte determinante de la organización social, de las reglas propias de la convivencia social, del intercambio de bienes y de las alianzas y resolución de conflictos" (Finol, 2007: 39-40).

En cierto sentido, aquí radica las notorias diferencias de concepción del mundo por parte de los wayuu y los "alijuna"3; estos últimos se inclinan más por el pensamiento científico, con el cual se ha desarrollado nuevas concepciones del mundo basadas en la razón; muy alejadas a los sueños, fantasías y fórmulas mágicas del pensamiento mítico.

\footnotetext{
${ }^{3}$ Los Wayuu asignaron el nombre de "Alijuna" a todas aquellas personas que no son de su etnia. "Ellos se denominan 'Wayúu' que significa 'Nosotros' o 'Gente'. A todos los que no somos indígenas nos llaman ‘Alijuna' que significa 'Extranjeros'” (Solano y Delgado, 2010: 3).
} 


\section{LA VENGANZA DE LA SANGRE}

Para los Wayuu la sangre es sinónimo de vida y, por eso, evitan celosamente su derramamiento y el quebranto de este elemento amerita un pago del infractor por el problema causado. Lo primordial para ello es compensar y que sea una indemnizada la falta; pero una violación o negación al acuerdo para resarcir la ofensa provoca entre los Wayuu un "exagerado derecho a la venganza", por lo que se cobra violentamente la falta y debe ser reintegrada de manera semejante: sangre por sangre, al estilo de la ley del talión.

"Cuando la mujer queda embarazada deja de menstruar, entonces la sangre que se queda en el cuerpo de la mujeres es lo que da origen al nuevo ser: He aquí la explicación del carácter sagrado de la sangre, la cual tiene una importancia relevante en las normas sociales de parentesco, que identifican a los clanes en particular y a toda la comunidad wayúu en general" (Pinzón Sánchez, 1990: 6566).

Por ese mismo vínculo de sangre, aunado a la marcada cultura matrilineal de los Wayuu, la ofensa a uno de sus miembros no es visto como un problema individual sino grupal, que afecta por igual a la familia del agraviado. "La responsabilidad ante un delito se asume de forma colectiva, es decir, cuando un wayuu actúa fuera de ley, la falta se extiende a su propio seno familiar materno" (Pocaterra, 2009: 71). Entonces bien, son los parientes uterinos quienes suelen mostrar su fuerza a la familia del agresor; siempre a través de un cálculo que les permita restablecer su dignidad dentro de la comunidad Wayuu, teniendo en cuenta el menor costo de vida posible y el mayor número de bienestar para su entorno familiar.

En este sentido, al momento de un crimen en la sociedad Wayuu, existe una serie de signos muy marcados que inducen a la venganza ante el derramamiento de sangre. Aunque la primera opción a seguir es siempre la negociación para salir del conflicto social, entre la familia de la víctima y la del victimario. Es cuando entra en escena el denominado "pütchipü'ü" o mejor conocido como "palabrero" (intermediario).

El "pütchipü'ü" siempre busca mediar entre las partes y conseguir el resarcimiento del desagravio. El pago por una ofensa es a través de bienes materiales, animales y otros; en tiempos actuales, la cancelación en dinero, como objeto de valor, ha empezado a ser común entre los Wayuu, lo cual anteriormente no era bien visto por sus miembros y era, incluso, hasta repudiado por no ser un elemento para el bienestar colectivo de la familia afectada.

"En la resolución de los conflictos, se nombra un pütchipü'ü, persona conocedora de las leyes, ampliamente conocido, de actuación imparcial, con solvencia moral y reconocida autoridad tradicional, para cumplir con el Amaúnajaa, utilizando la fuerza de la palabra o Pütchi, cuyo objetivo es lograr el equilibrio y la paz social. En la ley dentro de la sociedad wayuu, existe un profundo respeto al valor de la palabra, los acuerdos y los compromisos adquiridos" (Pocaterra: 2009: 71).

Cuando el agresor o sus familiares se rehúsan a indemnizar el derramamiento de sangre, se produce una ruptura de la intermediación, una negación al valor de la palabra y, en consecuencia, puede sobrevenir un enfrentamiento armado entre las 
partes. Según el etnólogo David Hernández-Palmar, para que una familia Wayuu cobre una venganza de manera inmediata es porque se rompió previamente, con un derramamiento de sangre, el acuerdo sostenido de palabra o que éste nunca se haya concretado.

\subsection{EL "EJITTAWAA" Y LA BÚSQUEDA DEL ASESINO}

Ciertamente existe una serie de rituales que, en primer lugar, se practican alrededor del crimen wayuu por los familiares de la víctima y que va ligada, indiscutiblemente, a la venganza de la ofensa. Hay que recalcar que, más allá de ser ritos mitológicos Wayuu, ésta obedece a una ritualización; es decir, a acciones que no cumplen funciones pragmáticas, pues su significado comunicativosimbólico es mucho más importante que su misma práctica.

Por ser la etnia Wayuu una sociedad marcada por la convivencia matrilineal, como se ha mencionado anteriormente, son las mujeres las encargadas de hacer velar el cobro de la venganza; son ellas, precisamente, las principales practicantes de esta serie de ritos de venganza mortuoria. Muchos de estos tienen un común denominador, más allá de la obvia venganza, y es la utilización de ciertos elementos de color rojo: tonalidad que para los Wayuu, explica Hernández-Palmar, "es una especie de talismán que equivocadamente se asocia a la venganza, cuando verdaderamente simboliza protección".

Una de estas ritualizaciones, ejercida sobre el cuerpo de la víctima, es el "ejittawaa" que en castellano significa atar. Éste es un rito practicado por las mujeres wayuu, donde amarran los pies del cadáver con una cinta roja para mantener afianzado o sujeto al agresor en la zona del crimen (ver foto 1). Es, sin duda, un signo del llamado a la venganza entre los Wayuu, muy común entre los primigenios de la Guajira colombiana y que, por la inexistencia de frontera para los Wayuu, su implementación en Venezuela se ha hecho habitual.

Este tipo de ritual no tiene un mito fundador como tal; pero si se ha hecho recurrente gracias a los sueños mitológicos wayuu, impregnados de una alta carga simbólica y surrealista, que da explicaciones claras de muchas de sus costumbres cotidianas en el plano real. "Vivimos soñando y ritualizando, lo que nos permite expresar conductas y actitudes que se nutren día a día del mundo mágico religioso wayuu" (Fernández en Pereira 2004: 41).

“(...) las prácticas oníricas de estas sociedades forman parte de su visión del mundo. De igual manera, se deben tomar en cuenta las claves de interpretación y sus relaciones con el pensamiento mítico, puesto que éste produce a menudo el marco de referencia axiológica y social de aquéllas, es decir, las normas, valores e ideales de la sociedad que sustentan los códigos oníricos" (Fernández y Finol, 2010: 2). 


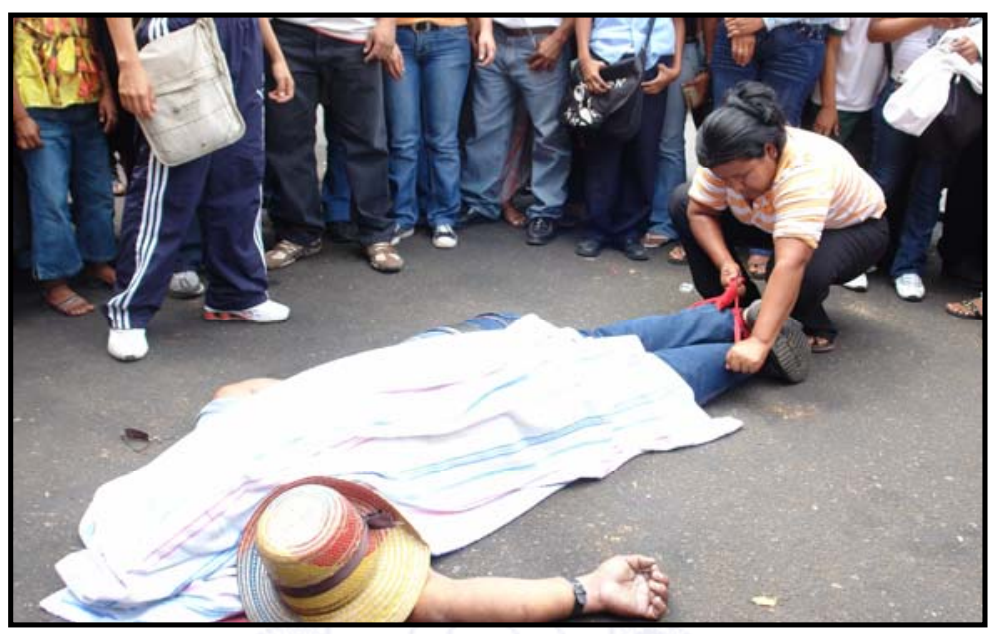

Foto 1: El "ejittawaa" es practicado por las mujeres wayuu en los pies de la víctima, en plena escena del crimen. (Foto cortesía: Eduard Ortega)

De esta manera, el "ejittawaa" es un rito que se ha practicado entre los Wayuu gracias a los sueños 4 . Aún cuando no tiene un mito fundacional conocido, su acción ritual se mitificó a través de los códigos oníricos y, por lo tanto, incorporada al mundo real gracias a su carga simbólica.

En el eje sintáctico Espacio - Tiempo - Objeto ritual, el amarre se efectúa en la propia escena del crimen, por ser ese el lugar del que se quiere evitar que huya el asesino. Esta práctica se hace tras un acuerdo de venganza entre los miembros de la familia, pero serán las mujeres quienes practiquen el "ejittawaa" sobre los pies del cadáver. Para su implementación, se puede utilizar cualquier tipo de material que sirva para amarrar, siempre y cuando sea de color rojo; incluso, hay quienes hacen jirones de las mantas guajiras para hacer este rito.

\subsection{EL ROJO DE LA VENGANZA}

Una segunda acción ritual, muy marcada en la venganza Wayuu, es que las mujeres utilicen mantas guajiras de color rojo, la cual se convierte en un signo de peligro para los familiares del agresor (ver Foto 2). A pesar de ser las damas quienes pavoneen la búsqueda del pago del desagravio (venganza), serán los hermanos del muerto o, en su defecto sus primos hermanos u hombres de la familia materna, los que cobrarán con sangre la deuda.

\footnotetext{
4 Los sueños son de vital importancia para los wayuu, pues son señales premonitorias, prescriptitas, orientadoras y de enseñanza para la vida, y de protección para el cuerpo y el espíritu; además advierten, de cierta manera, de todos aquellos males que afecten el equilibrio social y del ser.
} 
El espacio para este rito es la escena del crimen e, incluso, durante el entierro para que la vestimenta sea apreciada por los familiares del victimario y éstos sepan que la sangre derramada será cobrada. También se hace tras un acuerdo de venganza, entre las mujeres de la familia. Se utiliza cualquier vestimenta de color rojo, preferiblemente la manta guajira, lo que marca una amplia diferencia con el tradicional luto negro.

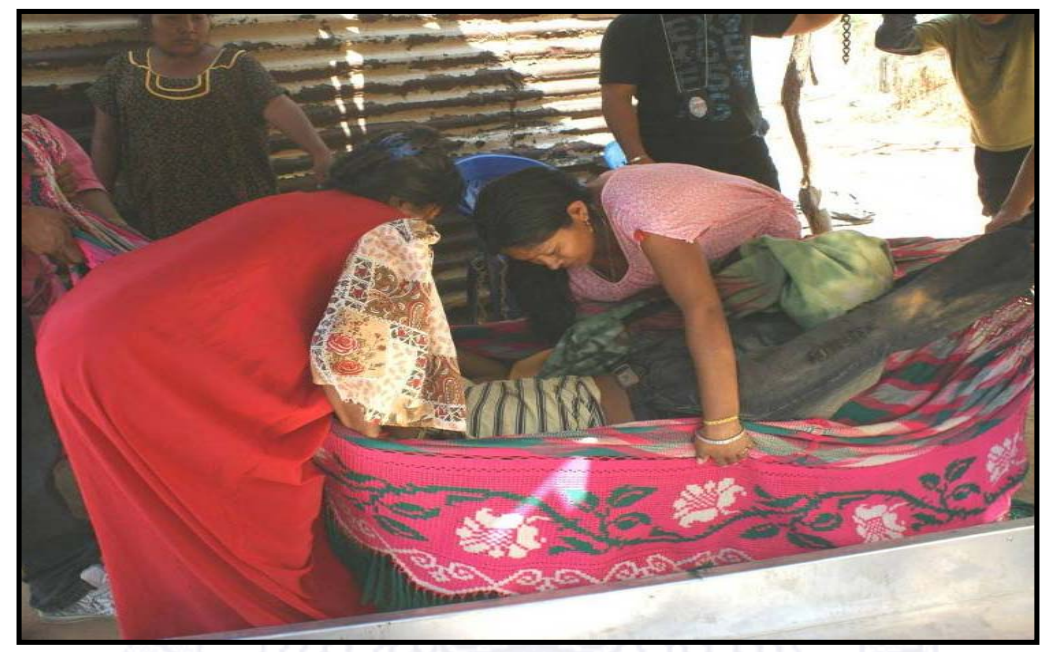

Foto 2: Las mujeres visten de rojo como señal de venganza, la sangre de la víctima será cobrada a la familia del agresor. (Foto cortesía: Jaidy Guevara)

Existen también otras acciones rituales de venganza o que, por lo menos, giran alrededor de las víctimas de muertes violentas dentro de la cultura Wayuu. Por ejemplo, en la Guajira colombiana, se acostumbra a colocarle monedas en cada una de las heridas (sólo sin son hechas por armas de fuego) durante la preparación del cuerpo para el entierro, como símbolo de una cobranza a los daños hechos a la carne ${ }^{5}$ Wayuu.

Quien cae en una muerte violenta no será velado, a diferencia del que muere por causas naturales, para evitar que el espíritu maligno salga del cuerpo antes de que el desagravio sea cobrado con sangre; en este mismo sentido, el levantamiento del cadáver, por parte de mujeres wayuu, es un rito para preservar la fuerza de los hombres en las batallas. Éste está asociado a la mitología del combate, donde se cree que el hombre que entra en contacto con un muerto caído de manera violenta pierde "el valor del combate" y será alcanzado por la muerte.

Un aparte a este tema de la venganza, es que el wayuu muerto siempre es acostado en un chinchorro, esto debido a que está asociado al ciclo de vida wayuu: En ellos se nace, se descansa, se duerme y se muere.

\footnotetext{
${ }^{5}$ La carne (o piel) para los wayuu tiene un significado similar al de la sangre. Para ellos la carne o "e'rukuu" le da el sentido de definición familiar, lo que para los occidentales es el clan.
} 


\section{EL ENCIERRO Y EL ORDEN SOCIAL}

El homicidio, dentro de la sociedad Wayuu, niega y se contrapone al comportamiento legitimado por su sociedad, por ser una violación a la organización social. "El crimen no implica una responsabilidad individual como en nuestra sociedad, sino un acto cometido por la intervención de poderes del mal que son los causantes reales de todo desorden" (Segovia, 2007: www).

En el universo mitológico wayuu, se consiguen muchas explicaciones del origen de los fenómenos naturales y sociales inmersos en su identidad cultural y conocidos gracias a sus relatos, donde se le da estructura a su organización de vida y sentido a cada una de sus acciones sociales para la resolución de conflictos.

La forma de ejercer ley, entre los "alijuna" y los Wayuu, es totalmente diferente; los primeros se rigen por un Código Civil Penal, mientras que los otros se rigen por la "Ley Guajira", la cual es aceptada y respetada por el Estado según el reconocimiento dado en la Constitución de la República Bolivariana de Venezuela y la Constitución de la República de Colombia; tras haber cometido un crimen, la familia del agresor debe resarcir la falta y, a la vez, buscar la purificación espiritual de quién cometió el homicidio, pues el grupo social debe recobrar su "statu-quo".

Una ritualización muy común entre los wayuu es el encierro o "Asülajawaa", que no son más que ritos de pasaje, prevención o purificación que permiten, para el primero, un ciclo de enseñanza y, para los otros, restablecer las normas quebrantadas por el mal en esta comunidad.

Para los wayuu, el hombre no es el verdadero culpable de un crimen: el espíritu maligno "Wanülüü", asociado también a la desarmonía y las enfermedades, es el único responsable y debe ser expulsado a través del Encierro de Purificación.

"En el caso del Wayuu, el tipo de mal amerita la intervención del mundo sagradoespiritual Pülasü, es el mal Wanülüü. Esto, debido a que, como es un mal generado por la incidencia de seres espirituales como Pulowi, Yoluja o Wanülüü, seres igualmente Pülasü, se necesita la intervención de un plano de "realidad" espiritual para poder curarlo" (Balza-García, 2010: 97).

El "Asülajawaa" es considerado como un proceso terapéutico o rito de curación, puesto que se necesita del encierro temporal y espacial para enfrentar los males espirituales, que a su vez pueden causar males colectivos en los Wayuu dentro de su estructura social y cultural. Es por ello que estos tipos de "enfermedades" o contaminaciones espirituales son tratadas como graves, por provenir del mundo de las deidades o figuras mitológicas.

Balza-García (2010) muestra una diferencia semiótica entre los niveles de gravedad de una enfermedad y señala que entre "menos grave" sea el padecimiento, es mayor el uso de elementos físicos para su tratamiento; mientras que si el mal es provocado por seres espirituales, como los Wanülüü, su

\footnotetext{
${ }^{6}$ Wanülüü es una figura mitológica Wayuu, que se opone a Maleiwa; está considerado como un ser destructor de todo cuanto se lo propone. La fuerza Wanülüü está acompañada del hambre, la sequía, las pestes, las enfermedades o el mal.
} 
tratamiento dependerá de elementos más simbólicos dentro de complejos ritos y es considerado como una enfermedad mayor.

Este rito de purificación busca restituir, como fin ulterior, el orden social entre los Wayuu, quebrado previamente por quién cometió el crimen y se contaminó por el Wanülüü; pero ese desorden involucra al cuerpo, por lo que Segovia (2007: www) señala que se debe procurar "sacarle el mal para que no siga matando".

El ritual del encierro no es sólo para quien haya cometido un asesinato y desee someterse al orden normativo Wayuu, sino también para quien haya comparecido ante la justicia formal (colombiana o venezolana), pues es una filtración del mal para el alma y el cuerpo y, por ende, "debe pasar por un segundo castigo" (Segovia, 2001: 142).

El contagio de un wayuu con fuerzas del mal requiere de un ritual sagrado para su purificación, el cual conlleva una serie de privaciones (libertad momentánea, algunos alimentos, contacto con el mundo exterior) y hasta un castigo.

En este sentido, tradicionalmente el rito del encierro presenta una trilogía de eventos: "Baño, encierro y comilona"; pero éste varía según la familia practicante y la gravedad de la falta cometida. Un análisis semiótico a este rito demuestra un rico mundo simbólico inmerso para la purificación del alma y la redención social del cuerpo; pero que también incurre en una penalización por parte de su familia.

"Cuando a un wayuu se le somete al rito del encierro se yergue y se potencia de manera extraordinaria todo su universo social y simbólico. El rito del encierro realizado al wayuu que ha permanecido en la cárcel (al igual que para quien no se haya compadecido ante norma judicial formal del Estado), ese lugar de otros, trasiega, supera o neutraliza lo que podría ser inicialmente una pérdida temporal, pero abrumadora, de todos sus valores. Cuando el wayuu vive el encierro ritual vive en carne propia la confrontación y el poder de todo lo que implica y significa su cultura" (Segovia, 2001: 140).

\subsection{SINTAXIS Y SEMIÓTICA RITUAL DEL ENCIERRO}

"El asülajawaa es un rito determinado por los sueños que busca impedir, mediante la abstención y la purificación, el cumplimiento de premoniciones negativas y restablecer el equilibrio social amenazado" (Fernández y Finol, 2010: 1). Aunque no solamente el encierro es para prevenir o purificar el alma contaminada, pues las majayuras (majayülü) o señoritas son encerradas al momento de tener su primera menstruación ${ }^{7}$.

En el caso del encierro de purificación del alma, se efectuó un esbozo sintáctico de la acción ritual, la cual constituye de 14 pasos elementales (ver Cuadro 1) y

\footnotetext{
7 "En este período, la niña es aislada de la comunidad para ser instruida por las mujeres mayores de su clan (abuela o madre) en el hilado, tejido y significado de los dibujos y los sueños. Es en ese momento cuando aprenden la importancia del tejido y del papel que deben desempeñar como mujer dentro de la sociedad wayuu" (Pocaterra, 2009: 146)
} 
que puede variar el número de consideraciones y elementos simbólicos según la familia practicante o la gravedad de la falta cometida. Existen tres actantes principales en la ritualización: el encerrado, el celebrante del rito y el colectivo social, los cuales serán a partir de ahora denominados como A1 (encerrado), A2 (celebrante) y A3 (comunidad).

Paso $N^{\circ}$ 1, el "recibimiento nocturno por la anciana": Esto da el comienzo ritual al asülajawaa. A1 es acogido por A2, quien será siempre una anciana, la mujer de mayor experiencia de su familia materna: abuela, tía o su propia madre, por ser precisamente las féminas las portadoras del Alanía $^{8}$, lo que las convierte en el chamán de la curación; así mismo, es importante que el rito comience en la medianoche para que nadie observe la llegada de $A 1$, como reforzamiento del sentido simbólico del encierro, tanto de pasaje como de purificación, el cual no es otra cosa que el secreto; es mantener al practicante en aislamiento del mundo exterior.

Balza-García (2010) da otra explicación de la noche como tiempo ritual del encierro, al señalar que es en la oscuridad nocturna cuando los Yolujas, espíritus aliados de los Wanülüü, salen a robarse el $A a^{\prime} i^{9}$ de los wayuu. Esto daría sentido, además, a que las expulsiones de entes malignos sean en horas nocturnas para que se reencuentre con su plano o mundo espiritual.

Paso $N^{\circ}$ 2, la "quema de la ropa usada": Esto obedece a la eliminación de elementos que hayan estado contaminados por la presencia Wanülüü. Con la destrucción de la ropa puesta al fuego, se corta todo tipo de elemento "infeccioso" que pueda ser contagioso para A1 o para cualquier otro miembro de la familia. Es parte de la purificación del entorno social. "En el caso de la contaminación, la salud y el orden del cuerpo Wayüu pueden muy bien regresar en su mayoría con sólo identificar el sujeto u objeto que lo produjo" (Balza-García, 2010: 102). Al quemarse, se elimina ese vínculo que mantuvo el hombre con el espíritu maligno.

Paso No 3, el "baño con agua fría o chirinchi (aguardiente autóctono wayuu)": Esta acción se le practica a $A 1$, para purificarle el cuerpo y quitarle la contaminación del mal. Es realizada por A2 con agua fría, porque hace temblar al cuerpo y ayuda a la expulsión del ente maligno. En el caso del chirinchi, además de ser un líquido frío, deja impregnado su fuerte olor que espanta a los Yolujas, espíritus aliados de los Wanülüü.

Con el baño se limpia el cuerpo de cualquier tipo de inmundicia, incluso la suciedad espiritual. Mary Douglas, en su libro Pureza y Peligro (1973: 14), explica que "la suciedad ofende el orden (en este caso social). Su eliminación no es un movimiento negativo, sino un esfuerzo positivo por organizar el entorno".

Paso N 4, el "encierro en la habitación": Esta acción ritual refuerza el carácter de secreto y aislamiento del ritual. A1 ingresa protegido (con la ayuda de la Alanía de la anciana), depurado (con la quema de la ropa contaminada) y limpio (purificado con el baño). Fernández y Finol (2010) indican que el recinto o la habitación donde

\footnotetext{
${ }^{8}$ Alanía o lanía es la representación física de espíritus ancestrales Wayuu, encargado de servir como "contra" o amuleto ante las desgracias y males.

${ }^{9}$ El Aa'in representa la fuerza vital de los wayuu.
} 
se practica el encierro se convierten en un espacio sagrado y por ende prohibido; el asilamiento toma un manto de sacralidad, mientras que lo externo se transforma en profano. Este lugar será, generalmente, una enramada que está contiguo o aparte a la residencia para evitar el contacto con la comunidad tanto físico, para evitar el contagio del mal a otros miembros familiares, y visual, como reforzamiento del orden secreto.

Paso $N^{\circ}$ 5, "es acostado sobre un chinchorro alto": Esto permite mantener a A1 alejado del contacto físico del suelo, lo mantiene levitando en el espacio, y por ende evita el contacto con lo bajo. Esta explicación obedece a las presencias mitológicas de Juyá y Pulowi; la primera deidad relacionada a la vida, al frío, a lo alto y al cielo (el bien o lo celestial); mientras que el segundo tiende más a lo inverso: a la muerte, el calor, lo bajo, la tierra (lo malo o lo terrenal). Así mismo, con el uso del chinchorro se refuerza el ciclo vital wayuu, con lo que A1 se compromete a retomar un nuevo estilo de vida.

Paso $N^{\circ}$ 6, "la ventana es cubierta con una cortina roja": Por ser la ventana el sitio por donde entrará la luz del sol y el viento nocturno, ésta permite también el acceso a la habitación de los Yolujas que deambulan la Guajira en la noche. Por eso es cubierta con un trapo rojo que, como se dijo anteriormente, dicha tonalidad es un talismán para los wayuu. Hay quienes afirman también que este apego al color rojo se debe a la similitud de la sangre, que no es otra cosa que la fuente de vida del hombre.

Paso No 7, la "dieta líquida y de alimentos blandos": El etnólogo HernándezPalmar manifiesta que durante el encierro sólo se puede tomar chicha de maíz y comer alimentos blandos, tal es el caso de la yuca, papa y bolitas de maíz hervido. El uujool (chicha de maíz) es considerada por los wayuu como la "bebida de la vida" y por eso se convierte en la única toma que tiene permitida A1 durante el encierro. "La chicha de maíz, como producto alimenticio conjuga la tierra y el agua, ambos elementos esenciales para la reproducción de la vida animal y vegetal y, en consecuencia, garantizadores de la vida" (Fernández y Finol, 2010: 15); mientras que los alimentos vegetales blandos son obtenidos del suelo, lo que se contrapone a la carne animal.

Paso $N^{\circ}$ 8, la "anciana habla y reflexiona con el encerrado": A2, quien goza con vasta experiencia de la vida, hace caer en cuenta a A1 sobre la falta que cometió. Es una especie de maestra o de jueza, pues hace reflexionar del mal causado a su comunidad; es por ello que esta parte del rito tiene un fin pedagógico y se le da a conocer a A1 sobre todas las abstenciones con las que debe vivir en el encierro y de manera obediente. 


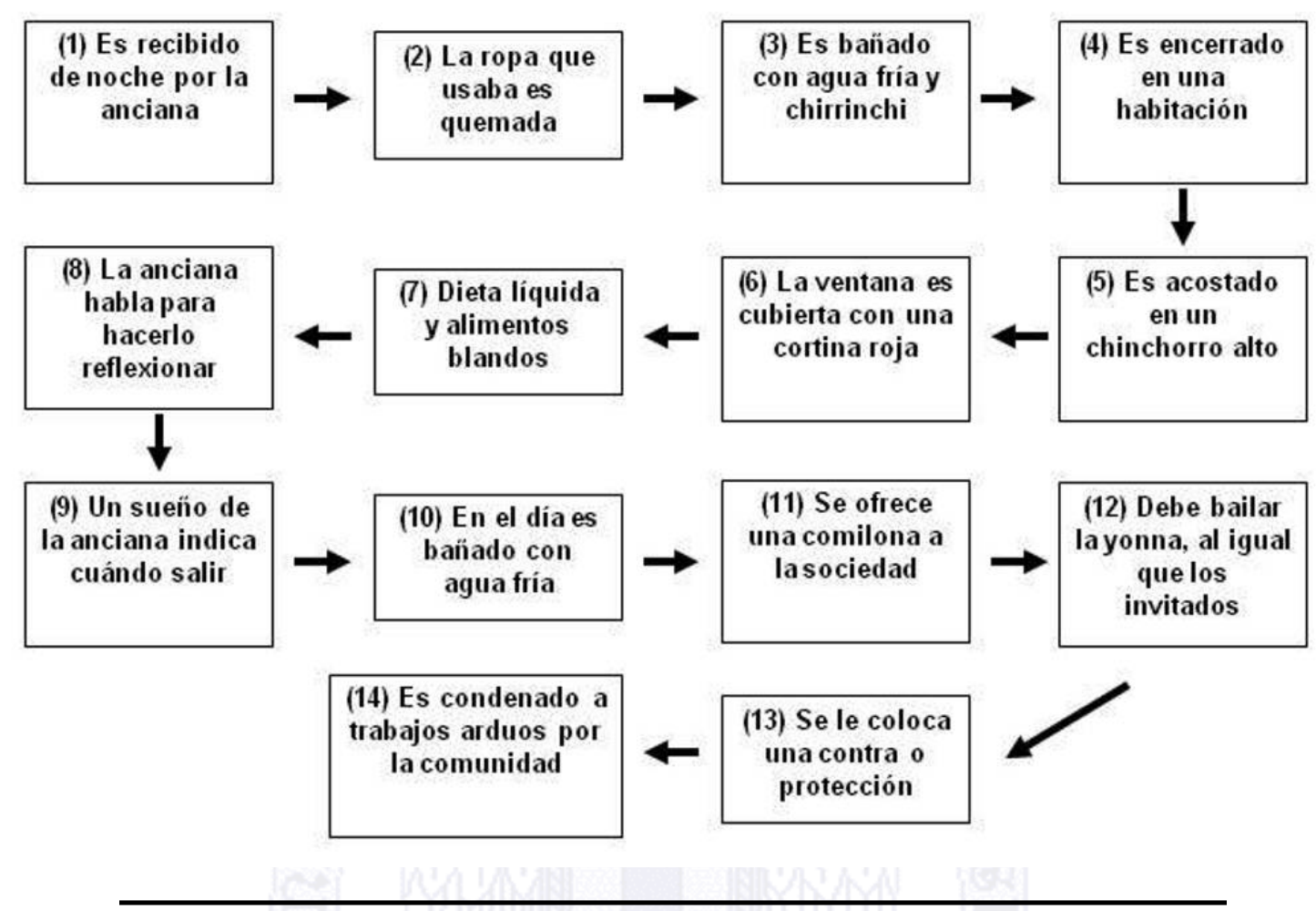

Cuadro $N^{\circ}$ 1: Sintaxis ritual del encierro de purificación del alma Wayuu

Paso $N^{\circ}$ 9, el "sueño de la anciana indica cuándo salir": No hay un tiempo ritual definido o determinado para el encierro. Su salida del aislamiento dependerá del Alapüjawaa, que no es más que un sueño sorpresivo y revelador, a través de mensajes imperativos; aún cuando la estadía puede variar según el tamaño del daño causado por A1 o la creencia de su grupo familiar, generalmente el encierro varía entre dos días y una semana.

Paso $N^{\circ} 10$, "es bañado en el día con agua fría": Con este escalafón del ritual se trata de borrar, a través del baño, cualquier rastro de impureza que A1 aún pueda mantener impregnada en su carne. Al expulsar la suciedad, explica Douglas, "no nos domina la angustia de escapar a la enfermedad sino que estamos reordenando positivamente nuestro entorno (Douglas, 1973: 14). El agua fría sirve nuevamente para evocar a Juyá y el tiempo ritual ya es en el día, primero, porque ya puede ser visto por cualquier miembro de la comunidad (el encierro terminó) y, además, porque de día se esconden los Yolujas.

Paso N ${ }^{0} 11$, es ofrecida "la comilona a la sociedad": Por ser la reinserción de A1 a la comunidad que, con el homicidio se deshonró, se agasaja a los invitados. Siempre se sacrifica uno o varios animales (según el estatus de la familia practicante), a veces chivos o pequeñas reses. Se brinda con uujool, chirinchi, ron o güisqui. Se hace una gran fiesta social, donde A3 come y bebe al igual que los 
espíritus invitados; el único que no puede comer del animal es $A 1$, quien se mantiene aislado de uno de los objetos que más atrae a las wanülüü, como son los animales, y evitar así una nueva contaminación.

Con esta celebración, se muestra que la sociedad wayuu dio su redención a A1, quien con el crimen trasgredió las normas de orden social en su comunidad. Además, "la comida un aspecto fundamental en la determinación del ser" wayuu, por su condición mitológica de origen de "Hombres-tigres". Y es que la comida representa el pago a los espíritus actuantes, tantos los buenos que ayudaron a alejarse a A1 de la enfermedad, como los espíritus malos que no pudieron comerse el alma de A1 y serán compensados con a carne del animal (Segovia, 1998: 18-27).

Paso $N^{\circ} 12$, el "baile de la Yonna": Esta ceremonia es una de las expresiones culturales del pueblo Wayuu, efectuada por diversos motivos sociales y espirituales, entre ellos por la curación de un enfermo (hay que recordar que A1 es tratado como un enfermo por su contaminación espiritual), por lo que este baile se convierte en un agradecimiento por la mejoría. "Si no lo hacen se morirán paulatinamente la familia de generación en generación como si fuera un pacto con el diablo" (Chacín, 2010: 73).

"La pareja de bailarines dibujan círculos sobre la arena; ella extiende su manta, la ensancha y el aire la mueve como una banderola... él cae al suelo y los gritos animan a otro bailarín para que acepte el reto... otra vez comienza la danza, así como la vida. (...) La vida renueva la esperanza, suple lo muerto y lo inerte en el eterno ciclo de lo desconocido, de los sueños y la fantasía" (Mujica Rojas, 2007: 94).

Paso № 13, la "colocación de la contra": Este escalafón le permite a A1 tener una protección perenne, una "contra" con poderes mágicos ante cualquier maleficio o ente maligno. Ésta es colocada en una de las extremidades del cuerpo de A1 para que la Alanía lo ayude a "neutralizar y evitar" los malos espíritus. Este amuleto debe ser rojo, un color talismán para los wayuu. La Contra es lo que va a garantizar la efectividad del encierro.

La "Contra" no sólo lo protege de las Wanülüü; sino también de otras entidades, tal y como lo explica Segovia:

"Sobre la persona que ha cometido el crimen queda el espíritu que lo ha llevado a la realización del mal; pero queda también el espíritu de la persona asesinada, en quien descansa la intención de vengarse de sus agresores, y esto exige la pérdida de la persona, ganando su muerte" (Segovia, 1998: 23).

Paso $N^{\circ} 14$, el "trabajo comunitario": Este es el aspecto punitivo del rito, pues A1 debe reponer el daño causado a su familia, lo cual refuerza la cohesión social y solidaridad social, elementos propios de su cultura. El trabajo puede variar con el cuido de un número mayor de animales durante el pastoreo, la construcción de nuevos espacios familiares o la recolección de las cosechas para la provisión de alimentos para la familia. 


\subsection{MITOLOGÍA WAYUU, VENGANZA Y WANÜLÜÜ}

Dentro del pensamiento del mito antropogónico Wayuu, hay una evidente relación entre la venganza del crimen dentro de su sociedad y la clara participación de las Wanülüu como provocadores de este mal individual y que, evidentemente, afecta el entorno social del asesino. Hilario Chacín, en su libro "Pueblo Wayuu: Un Misterio Develado" (2010: 58-59), así lo da a conocer a través del mito de "El Cerro Jimut":

“Un día un Wayuu llamado Japateerai quien venía de una fiesta en Mala'yapa'a pasó cerca del cerro a eso de las dos de la madrugada, cargaba una escopeta. Cuando Japateerai iba caminando a pie; Sintió el sonido de los frenos de una cabalgadura que venía enfrente y bajo el esplendor de la luna vio un hombre montado sobre un caballo blanco con la frente muy brillante. El Wayuu se escondió debajo de un trupillo frondoso y le disparó al Wanülüü botando chispa y una voz como si fuera de una gallina: "Kaaaaaaaa". El Wayuu se asustó, salió corriendo a su casa creyendo que era una persona de verdad lo que había matado.

Le contó a sus familiares, esa misma noche recogieron sus animales, corotos por temor a que los vayan a matar por culpa del asesino y como no hubo noticia de ningún muerto el matador se apersonó al lugar del crimen encontrando una boa enorme muerta y allí se dio cuenta de que el muerto no era ninguna persona, sino el espíritu maligno o wanülüü. Desde esa vez no se sintió más el martirio en el cerro".

Esta mitología hace un símil entre wanülüü y los Alijunas, muy posiblemente a los conquistadores españoles que llegaron cabalgando a caballos a estas tierras y posando sobre sus cabezas relucientes cascos de metales. Así mismo se demuestra como estos espíritus malignos tienta al Wayuu a cometer los crímenes.

De igual forma, refleja el sentido natural de la venganza wayuu ante un crimen y como esto puede crear un desequilibrio en el orden social del victimario, demostrando que la responsabilidad no es individual sino colectiva, pues sus familiares deberán correr con las consecuencias del desagravio cometido.

\section{CONCLUSIÓN}

En una sociedad como la Wayuu, donde los dramas y conflictos sociales son constantes, el mantenimiento de la cohesión y orden social es fundamental para sus miembros; son las compensaciones de las faltas cometidas y en otros casos las acciones rituales, muchas de ellas alrededor de la venganza y otras a través del encierro, las que evitan un mayor derramamiento de sangre entre los Wayuu, aunque para los occidentales esto parezca un tanto incoherente.

La lucha entre el bien y el mal (interno contra lo externo), reflejada en muchas de las mitologías originarias del ser Wayuu, el conflicto simbólico entre Juyá y Pulowi; sí como lo explica Pinzón: 
"La lucha de dos seres naturales y mitológicos que son opuestos, representa al hombre en Juyá y a la mujer en Pulowi. Esta lucha simboliza el antagonismo entre la vida y la muerte. La vida se manifiesta en el dominio de Juyá sobre Pulowi" (Pinzón, 1990: 63).

En este caso, en las acciones rituales estudiadas en esta investigación, es el crimen el causante del "mal", con una fuerte carga destructiva, y sólo la purificación del alma del asesinó, contaminada por las Wanülüü (la verdadera causante del crimen y no el hombre) la que permite recobrar el "bien" que desembocó un desorden en las estructuras sociales entre los miembros de la comunidad Wayuu.

La carga simbólica, reflejada en el rito del "encierro de purificación del alma" se demuestra en un detallado proceso de descontaminación espiritual, incluyendo allí también un elemento punitivo al practicante, como muestra de reparo social; tal y como lo dice Segovia (2001: 140):

¡El rito del encierro es sin duda uno de los elementos que muestran cómo esta sociedad a pesar de coquetear y asimilar nuevas pautas y exigencias ajenas a su campo social, crea a la vez, otros recursos que potencian el valor y la legitimidad de sus valores simbólicos frente a la manera de enfrentar sus articulares circunstancias!

\section{REFERENCIAS BIBLIOGRÁFICAS:}

a) (2010) BALZA-García, Rafael "El mal, jerarquía y función socio-simbólica en la cultura Wayuu: un enfoque simbólico". Espacio Abierto, Vol. 19 № 1, 93-115, Venezuela

b) (1990) BARTHES, Roland. La Aventura Semiológica. Ediciones Paidós Ibéricas S.A., Barcelona (España).

c) (1962) BRICEÑO GUERRERO, J. ¿Qué es la Filosofía? Publicación del Departamento de Orientación Profesional y Vocacional de la Universidad de Los Andes. Mérida (Venezuela).

d) (2010) CHACÍN, Hilario. El Pueblo Wayuu: Un Misterio Develado. Obra inédita registrada en la oficina del Derecho de Autor. <http://www.eibguajira.info.ve/pdf/misterios-develados.pdf.>

e) (1973) DOUGLAS, Mary. Pureza y Peligro: un análisis de los conceptos de contaminación y tabú. Siglo Veintiuno de España Editores. Madrid (España) 
f) (2010) FERNÁNDEZ, Dalia; FINOL, José Enrique. "Sueño y Sintaxis Ritual entre los wayuu". UNICA (Aceptado para publicación). Maracaibo (Venezuela).

g) (2007) FINOL, José Enrique. Mito y Cultura Guajira: contribución a la semiótica del mito guajiro. Ediciones del Vice Rectorado Académico de la Universidad del Zulia. Maracaibo (Venezuela)

h) (1981) GIOBELLINA BRUMANA, Fernando; GONZÁLEZ, Elda E. "Mito, Rito, Lévi-Strauss, Mary Douglas". Española de Antropología Americana, Vol. XI, 245257, Universidad Complutense de Madrid, Madrid (España).

i) (2010) HERNÁNDEZ-PALMAR, David. Entrevista personal con el etnólogo, comunicador social y documentalista Wayuu.

j) (2007) MUJICAS ROJAS, Jesús. Amüchi Wayuu: La Cerámica Guajira. Fundación Editorial El Perro y La Rana. Caracas (Venezuela).

k) (2004) PEREIRA, Gustavo. El legado indígena. Biblioteca Básica Temática, Consejo Nacional de la Cultura. Caracas (Venezuela).

I) (1990) PINZÓN SÁNCHEZ, Gustavo. "Incidencia del industrialismo en la cultura indígena guajira". Huellas, $\mathrm{N}^{\circ} 28,60-68$, Universidad del Norte, Barranquilla (Colombia).

m) (2009) POCATERRA GONZÁLEZ, Jorge. Los Wayuu, Na Wayuukana. Odebrecht, Venezuela.

n) (1998) SEGOVIA, Yanet. "Crimen y Otredad en la Sociedad Wayuu: Interpretación a partir del Significado Mítico del Mal”. Boletín Antropológico, № 44, 05-33, Universidad de Los Andes. Mérida (Venezuela).

ñ) (2001) SEGOVIA, Yanet. "La Cárcel no Cura: El Espacio como Experiencia Ética y Estética del Mal”. Cenipec, № 20, 129-150, Universidad de Los Andes. Mérida (Venezuela).

o) (2007) SEGOVIA, Yanet. "El crimen y el deber-ser en la sociedad Wayuu". Cenipec, No 18-19, Universidad de Los Andes. Mérida (Venezuela). <http://www.saber.ula.ve/handle/123456789/23594>

p) SOLANO PALMAR, Eulalia; DELGADO BRITO, Josefina (2010). Diccionario Wayuu-Guajiro. Publicaciones Avantis. Colombia.

q) (1969) VAN GENNEP, Arnold (1969). Los Ritos de Paso. Alianza Editorial. Madrid (España) 